\title{
The Effect of Metabolic Syndrome on Periodontal Disease in Korean Adults: Based on the Data from the 6th Korea National Health and Nutrition Examination Survey (2013 2015)
}

\author{
Jung-Hui Son ${ }^{1}$ and Soo-Myoung Bae ${ }^{2, \dagger}$ \\ 'Department of Dental Hygiene, Daewon University College, Jecheon 27135, \\ ${ }^{2}$ Department of Dental Hygiene, College of Dentistry \& Research Institute of Oral Science, Gangneung-Wonju \\ National University, Gangneung 25457, Korea
}

\begin{abstract}
Background: The purpose of this study was to evaluate the association between metabolic syndrome and periodontal disease in Korean adults.

Methods: This study analyzed the screening data of 12,686 adults aged $\geq 19$ years, including demographic characteristics, lifestyle habits, and each component of metabolic syndrome, obtained from the sixth Korea National Health and Nutrition Examination Survey database. Periodontal health status was measured by the community periodontal index. Subjects with three or more risk factors were considered as having metabolic syndrome. The Rao-Scott chi-square test was performed to assess the relationships between demographic characteristics, lifestyle habits, components of metabolic syndrome, and periodontal disease. Logistic regression analysis was performed based on the complex sample to evaluate the relationship between metabolic syndrome and periodontal disease.

Results: The prevalence of periodontal disease was higher among the subjects with advancing age, lower average household income and education level, those working in production, residents of eup-myeon areas, in past or current smoker, those with excessive alcohol consumption habit in a week, and reduced brushing frequency and the use of oral care products $(p<0.001)$. Each component of metabolic syndrome was associated with higher prevalence of periodontitis in the subjects with abnormal than in those with normal levels $(p<0.001)$. The prevalence of periodontal disease in subjects with metabolic syndrome was approximately 1.443 times higher than that in normal subjects (odds ratio, 1.443; $p<0.001$ ).

Conclusion: This study confirmed the association between metabolic syndrome and periodontitis in Korean adults, and further studies will be needed to determine the causal relationship between the two conditions.
\end{abstract}

Key Words: Korean adults, Metabolic syndrome, Periodontal disease

\section{Introduction}

Metabolic syndrome was first described by Reaven in 1988 as Syndrome X. Several risk foctors for cardiovascular disease have been reported to co-exist in an individual, which can substantially increase the clinical incidence of such conditions ${ }^{1}$. Since then, the initial concept has been developed and named as metabolic syndrome ${ }^{1)}$. A study reported that the frequency of major cardiovascular diseases was increased in patients with metabolic syndrome $^{2)}$. A five-fold increased risk of developing diabetes was reported in patients with metabolic syndrome, while a six-seven-fold increase was reported in those with a combination of metabolic syndrome and insulin resistance ${ }^{3)}$. The prevalence of metabolic syndrome has been increasing, and has recently attracted more attention. 
The prevalence of metabolic syndrome has been reported to increase with age, degree of obesity, and in those with reduced physical activity. Gingival health status is independently associated with each factor of metabolic syndrome, and presence of higher number of factors in an individual has been associated with greater risk of oral diseases such as periodontal disease. Patients with metabolic syndrome demonstrate deep periodontal pockets and a wide range of periodontal diseases compared to those without the syndrome. Patients at a high risk of metabolic syndrome harbor a similar risk for periodontal disease due to increased systemic inflammatory response even in the presence of minimal local risk factors ${ }^{4}$. Based on data from the National Health and Nutrition Examination Survey (US) conducted between 1988 and 1994, an analysis of 8,814 adults aged $\geq 20$ years reported that the prevalence of metabolic syndrome was $23.7 \%$. Subsequent analysis conducted in 2003 and 2006 revealed that $34 \%$ of the 3,423 adults surveyed (age $\geq 20$ years) suffered from metabolic syndrome, thereby demonstrating an increasing trend $^{5)}$. In South Korea, the prevalence of metabolic syndrome among elderly men and women ( $>65$ years of age) was $41.7 \%$ and $63.2 \%$, respectively, based on analysis of the 2007 Korea National Health and Nutrition Examination Survey database ${ }^{6}$.

In addition, the infection associated with periodontitis is not limited to the oral cavity. Bacteria and toxins that cause periodontal disease can migrate through the ulcer site of the periodontal pocket and enter the blood vessels. Certain periodontal bacteria can invade the immune system of the host, and cause widespread systemic inflammation in organs, including the heart, kidneys, lungs, brain, and embryos of infected pregnant women ${ }^{7}$. Periodontitis and metabolic syndrome are associated with systemic inflammation and insulin resistance, and the two diseases can be linked through a common pathophysiological pathway ${ }^{8)}$. Therefore, treatment and prevention of metabolic syndrome is important for maintenance of oral health prior to the onset of cardiovascular and other chronic diseases such as diabetes.

Recently, studies have been conducted on the association between periodontal disease and chronic diseases such as diabetes, cardiovascular disease, and hypertension that are common in Korean adults. However, there are no large-scale studies, and there is no national-level data on the correlation between metabolic syndrome and periodontal disease. Therefore, this study was conducted to evaluate the association between metabolic syndrome and periodontitis using data from the sixth Korea National Health and Nutrition Examination Survey (2013 2015).

\section{Materials and Methods}

\section{Study subjects}

The sixth Korea National Health and Nutrition Examination Survey used the two-stage stratified cluster sampling method to select subjects based on the extraction framework of the population and housing census data ${ }^{9}$. This was done to provide statistics that were representative and reliable indicators of the health status of the population.

The sixth survey area extracted 192 zones a year and 576 zones for 3 years. Twenty households were selected by sample extraction from among the appropriate establishments, excluding nursing homes, military facilities, prisons, and foreign households. From the sample households, all members above 1 year of age who met the recruitment criteria were selected as the survey subjects" .

In this study, out of the total 18,034 subjects aged $\geq 19$ years who participated in the sixth Korea National Health and Nutrition Examination Survey, 12,686 subjects for whom data on community periodontal index (CPI) and metabolic syndrome available were selected for the final analysis. The general characteristics considered were gender and age, average monthly household income, and education level of the subjects.

\section{Examination of periodontal condition}

Oral examination was performed by two public health dentists from the Korea Centers for Disease Control, and in the same year, the public health dentists who were trained for the survey researcher by the Korea National Health and Nutrition Examination Survey based on the examination criteria of the National Oral Health Survey. Periodontal examination was performed with the subjects seated on the chair (Verus series, TAURUS_Z; Shinheung Co. Ltd., Seoul, Korea). The teeth (\#11, 16, 17, 26, 27, 31, 
$36,37,46$, and 47) were examined using a periodontal probe and the CPI was calculated based on the test results.

\section{Survey}

The Korea National Health and Nutrition Examination Survey investigates subjective dental health awareness, toothache experience, tooth brushing frequency, experience of orthodontic treatment, rate of unmet medical treatment, experience of dental treatment from unqualified persons, details of routine visits to a dental clinic or hospital, and use of oral hygiene products, among other aspects in adults aged $\geq 19$ years. In this study, the lifestyle habits considered were the frequency of tooth brushing, periodic dental check-ups, and the use of oral hygiene products.

\section{Metabolic syndrome components}

Using data from the National Cholesterol Education Program and the criteria of the Korean Society of Obesity, metabolic syndrome was defined when there were three or more risk factors such as abdominal obesity, hypertension, high fasting glucose levels, and low levels of high-density lipoprotein (HDL) cholesterol.

(1) Abdominal obesity: waist circumference in man $\geq$ $90 \mathrm{~cm}$ and in woman $\geq 85 \mathrm{~cm}$

(2) Hypertension: systolic blood pressure $\geq 130 \mathrm{mmHg}$, diastolic blood pressure $\geq 85 \mathrm{mmHg}$

(3) Fasting glucose: $\geq 100 \mathrm{mg} / \mathrm{dL}$

(4) Hypertriglyceridemia: $\geq 150 \mathrm{mg} / \mathrm{dL}$

(5) Low HDL cholesterol: man $<40 \mathrm{mg} / \mathrm{dL}$, woman $<50 \mathrm{mg} / \mathrm{dL}$

Waist circumference of the subjects was measured using a tape (SECA 200; SECA, Hamburg, Germany), to one decimal point $(0.1 \mathrm{~cm})$ while breathing, after marking the midpoint between the lower end of the last rib and upper part of the iliac crest promoted in the mid-axillary line with a water pen. Blood pressure was measured by placing the stethoscope over the brachial artery, expanding the bar to a maximum inflation pressure at a rapid and constant rate, and steadily lowering the pressure at a rate of $2 \mathrm{mmHg}$ per pulse. After the blood pressure was measured, the pressure cuff was removed from the arm and the air was removed. The measurements were performed thrice with a resting interval of 30 seconds between each test, and the final blood pressure was calculated as an average of the second and third measurements. This study also assessed blood triglyceride, HDL cholesterol, and fasting glucose levels ${ }^{10}$.

\section{Data analysis}

Descriptive statistics were used to determine the distribution of socio-demographic characteristics, lifestyle, periodontitis, and metabolic syndrome in the subjects. In addition, the relationships between the aforementioned parameters and periodontitis were assessed. Subjects were classified as normal if the CPI score was 0 to 2 and as having periodontitis if the score was 3 to 4 . These values were utilized to perform the Rao-Scott chi-square test based on the composite samples. To assess the impact of metabolic syndrome on the risk of periodontitis, after controlling for gender, age, income, education level, occupation, and residence area as confusion variables, according to the presence and absence of periodontitis, it was divided into a case with three components of metabolic syndrome and a case with more than three components of metabolic syndrome to perform logistic regression analysis according to the composite samples. All statistical analyses were performed using software, SPSS statistics for Windows, ver. 17.0 (SPSS Inc., Chicago, IL, USA), with a significance level of 0.05 .

\section{Results}

\section{Prevalence of periodontal disease according to socio-demographic characteristics}

Of the 12,686 subjects, 8,717 (68.7\%) belonged to the normal group and 3,969 (31.3\%) to the periodontal disease group. As for gender, the status of periodontal disease was $23.1 \%$ for women and $33.7 \%$ for men, which was higher than that for women $(\mathrm{p}<0.001)$. The prevalence of periodontal disease was higher among those with lower income and education levels ( $\mathrm{p}<0.001)$. As for occupation, blue color showed higher prevalence of periodontal disease $(\mathrm{p}<0.001)$. Moreover, the prevalence was higher among subjects living in eup-myeon areas than those living in the dong area $(\mathrm{p}<0.001)($ Table 1$)$. 
Jung-Hui Son and Soo-Myoung Bae : The Effect of Metabolic Syndrome on Periodontal Disease in Korean Adults

Table 1. Distribution of Periodontal Disease according to Socio-Demographic Characteristics of Study Subjects

\begin{tabular}{|c|c|c|c|c|}
\hline Variable & Total $(n=12,686)$ & $\operatorname{Normal}^{\mathrm{a}}(\mathrm{n}=8,717)$ & Periodontitis $^{\mathrm{a}}(\mathrm{n}=3,969)$ & p-value ${ }^{b}$ \\
\hline Gender & & & & $<0.001$ \\
\hline Man & $5,432(100.0)$ & $3,331(66.3)$ & $2,101(33.7)$ & \\
\hline Woman & $7,254(100.0)$ & $5,386(76.9)$ & $1,868(23.1)$ & \\
\hline Age (y) & & & & $<0.001$ \\
\hline $19 \sim 29$ & $1,662(100.0)$ & $1,593(95.6)$ & $69(4.4)$ & \\
\hline $30 \sim 39$ & $2,157(100.0)$ & $1,845(84.5)$ & $312(15.5)$ & \\
\hline $40 \sim 49$ & $2,427(100.0)$ & 1,739 (69.6) & $688(30.4)$ & \\
\hline $50 \sim 59$ & $2,624(100.0)$ & $1,510(55.4)$ & $1,114(44.6)$ & \\
\hline $60 \sim 69$ & $2,241(100.0)$ & $1,195(52.5)$ & $1,046(47.5)$ & \\
\hline$\geq 70$ & $1,575(100.0)$ & $835(52.6)$ & $740(47.4)$ & \\
\hline Household income (won) & & & & $<0.001$ \\
\hline Low & $2,117(100.0)$ & $1,202(59.4)$ & 915 (40.6) & \\
\hline Lower middle (mid-low) & $3,231(100.0)$ & $2,143(69.6)$ & $1,088(30.4)$ & \\
\hline Upper middle (mid-high) & $3,577(100.0)$ & $2,587(74.4)$ & $990(25.6)$ & \\
\hline High & $3,761(100.0)$ & $2,785(75.7)$ & $976(24.3)$ & \\
\hline Education level & & & & $<0.001$ \\
\hline$\leq$ Primary school & $2,612(100.0)$ & $1,386(52.3)$ & $1,226(47.7)$ & \\
\hline Middle school & $1,345(100.0)$ & $760(56.3)$ & $585(43.7)$ & \\
\hline High school & $4,472(100.0)$ & $3,209(74.1)$ & $1,263(25.9)$ & \\
\hline$\geq$ University or college & $4,257(100.0)$ & $3,362(80.1)$ & 895 (19.9) & \\
\hline Occupation & & & & $<0.001$ \\
\hline Jobless & $5,009(100.0)$ & $3,500(73.8)$ & $1,509(26.2)$ & \\
\hline Blue color & $4,692(100.0)$ & $2,897(64.9)$ & $1,795(35.1)$ & \\
\hline White color & 2,985 (100.0) & $2,320(78.0)$ & $665(22.0)$ & \\
\hline Residential district & & & & $<0.001$ \\
\hline Dong & $10,392(100.0)$ & 7,391 (73.7) & $3,001(26.3)$ & \\
\hline Eup-myeon & 2,294 (100.0) & $1,326(61.2)$ & $968(38.8)$ & \\
\hline
\end{tabular}

Values are presented as number $(\%)$.

${ }^{\mathrm{a}}$ Normal, probing pocket $<4 \mathrm{~mm}$ periodontitis, probing pocket $\geq 4 \mathrm{~mm}$.

${ }^{\mathrm{b}} \mathrm{p}$-value by $\chi^{2}$ test.

\section{Prevalence of periodontal disease according to lifestyle habits}

The prevalence of periodontal disease based on the frequency of tooth brushing per day was $40.7 \%, 31.4 \%$, and $23.9 \%$ among those who brushed less than one time, twice, and more than thrice, respectively. The results demonstrated that lower frequency of tooth brushing was associated with higher prevalence of periodontal disease $(\mathrm{p}<0.001)$. The prevalence of periodontal disease based on the use of auxiliary oral hygiene products was $32.7 \%$ among non-users as compared to $24.5 \%$ among those who used the products $(\mathrm{p}<0.001)$. There was no statistically significant difference in the prevalence of periodontal disease according to dental examination experience $(p=0.348)$. The prevalence of periodontal disease was
$38.6 \%$ in current smokers, $36.8 \%$ in former smokers, and $22.0 \%$ in non-smokers $(\mathrm{p}<0.001)$. High-risk drinkers demonstrated an increased prevalence than low-risk drinkers $(\mathrm{p}<0.001)$ (Table 2).

\section{Prevalence of periodontal disease according to metabolic syndrome components}

The prevalence of periodontal disease was $37.9 \%$ among the subjects with abnormal waist circumference (men $\geq 90 \mathrm{~cm}$, women $\geq 85 \mathrm{~cm}$ ), whereas that among those with normal circumference (men $<90 \mathrm{~cm}$, women $<85 \mathrm{~cm}$ ) was $25.4 \%$. The fasting plasma glucose level ( $\geq$ $100 \mathrm{mg} / \mathrm{dL}$ ) was $42.1 \%$ and the prevalence of periodontal disease was higher than that of the normal group (22.6\%) $(p<0.001)$. Likewise, subjects with abnormal levels of 
Table 2. Distribution of Periodontal Disease according to Lifestyle Characteristics of Study Subjects

\begin{tabular}{|c|c|c|c|c|}
\hline Variable & Total $(n=12,686)$ & $\operatorname{Normal}^{\mathrm{a}}(\mathrm{n}=8,717)$ & Periodontitis $^{\mathrm{a}}(\mathrm{n}=3,969)$ & p-value ${ }^{b}$ \\
\hline Toothbrushing frequency a day & & & & $<0.001$ \\
\hline$\leq 1$ & $1,352(100.0)$ & $753(59.3)$ & $599(40.7)$ & \\
\hline 2 & $4,805(100.0)$ & $3,173(68.6)$ & $1,632(31.4)$ & \\
\hline$\geq 3$ & $6,529(100.0)$ & $4,791(76.1)$ & $1,738(23.9)$ & \\
\hline The use of proxabrush/dental floss & & & & $<0.001$ \\
\hline Use & $6,575(100.0)$ & $4,838(75.5)$ & $1,737(24.5)$ & \\
\hline Non-use & $6,111(100.0)$ & $3,879(67.3)$ & $2,232(32.7)$ & \\
\hline The experience of receiving a dental exam ${ }^{c}$ & & & & 0.348 \\
\hline Yes & $3,848(100.0)$ & $1,150(27.7)$ & $2,698(72.3)$ & \\
\hline No & $8,838(100.0)$ & $2,819(28.7)$ & $6,019(71.3)$ & \\
\hline Smoking status & & & & $<0.001$ \\
\hline Never smoker & $8,071(100.0)$ & $6,017(78.0)$ & $2,054(22.0)$ & \\
\hline Ex-smoker & $2,275(100.0)$ & $1,346(63.2)$ & $929(36.8)$ & \\
\hline Current smoker & $2,340(100.0)$ & $1,354(61.4)$ & $986(38.6)$ & \\
\hline Drinking $^{\mathrm{d}}$ & & & & $<0.001$ \\
\hline Non-drinker & $5,743(100.0)$ & $3,891(70.3)$ & $1,852(29.7)$ & \\
\hline Low & $5,611(100.0)$ & $3,973(74.3)$ & $1,638(25.7)$ & \\
\hline High & $1,332(100.0)$ & $853(65.8)$ & $479(34.2)$ & \\
\hline
\end{tabular}

Values are presented as number $(\%)$.

${ }^{a}$ Normal, probing pocket $<4$ mmperiodontitis, probing pocket $\geq 4 \mathrm{~mm}$.

b-value by $\chi^{2}$ test.

${ }^{\mathrm{c}}$ During last 1year dental checkup.

${ }^{\mathrm{d}}$ Mean frequency of drinking a week.

Table 3. Relationships between the Presence of Periodontitis and the Components of Metabolic Syndrome

\begin{tabular}{|c|c|c|c|c|}
\hline Component of metabolic syndrome & Total $(n=12,686)$ & $\operatorname{Normal}^{\mathrm{a}}(\mathrm{n}=8,717)$ & Periodontitis $^{\mathrm{a}}(\mathrm{n}=3,969)$ & p-value ${ }^{b}$ \\
\hline Waist circumference $(\mathrm{cm})^{\mathrm{c}}$ & & & & $<0.001$ \\
\hline Man $<90$, Woman $<85$ & $9,418(100.0)$ & $6,765(74.6)$ & $2,653(25.4)$ & \\
\hline Man $\geq 90$, Woman $\geq 85$ & $3,268(100.0)$ & $1,952(62.1)$ & $1,316(37.9)$ & \\
\hline Fasting blood glucose $(\mathrm{mg} / \mathrm{dL})^{\mathrm{c}}$ & & & & $<0.001$ \\
\hline$<100$ & $8,589(100.0)$ & $6,407(77.4)$ & $2,182(22.6)$ & \\
\hline$\geq 100$ & $4,097(100.0)$ & $2,310(57.9)$ & $1,787(42.1)$ & \\
\hline Low HDL-cholesterol $(\mathrm{mg} / \mathrm{dL})^{c}$ & & & & $<0.001$ \\
\hline Man $\geq 40$, Woman $\geq 50$ & $8,343(100.0)$ & $5,951(74.5)$ & $2,392(25.5)$ & \\
\hline Man $<40$, Woman $<50$ & $4,343(100.0)$ & $2,766(65.3)$ & $1,577(34.7)$ & \\
\hline Triglycerides (mg/dL) & & & & $<0.001$ \\
\hline$<150$ & $9,016(100.0)$ & $6,505(75.7)$ & $2,511(24.3)$ & \\
\hline$\geq 150$ & $3,670(100.0)$ & $2,212(61.7)$ & $1,458(38.3)$ & \\
\hline Blood pressure $(\mathrm{mmHg})^{\mathrm{c}}$ & & & & $<0.001$ \\
\hline $\mathrm{SBP}<130$ and $\mathrm{DBP}<85$ & $9,077(100.0)$ & $6,641(75.8)$ & $2,436(24.2)$ & \\
\hline $\mathrm{SBP} \geq 130$ or $\mathrm{DBP} \geq 85$ & $3,609(100.0)$ & $2,076(59.5)$ & $1,533(40.5)$ & \\
\hline Metabolic syndrome $^{c}$ & & & & $<0.001$ \\
\hline No & $9,692(100.0)$ & $7,060(75.8)$ & $2,632(24.2)$ & \\
\hline Yes & 2,994 (100.0) & $1,657(56.3)$ & $1,337(43.7)$ & \\
\hline
\end{tabular}

Values are presented as number (\%).

HDL: high-density lipoprotein, SBP: systolic blood pressure, DBP: diastolic blood pressure.

${ }^{a}$ Normal, probing pocket $<4 \mathrm{~mm}$; periodontitis, probing pocket $\geq 4 \mathrm{~mm}$.

${ }^{\mathrm{b}} \mathrm{p}$-value by $\chi^{2}$ test.

${ }^{\mathrm{c}}$ Adjusted for age, gender, house income, education level, residential district. 
HDL cholesterol (male $<40 \mathrm{mg} / \mathrm{dL}$, female $<50 \mathrm{mg} / \mathrm{dL}$ ) were associated with higher prevalence of periodontal disease $(34.7 \%)$ compared to the $25.5 \%$ observed among those with normal levels $(\mathrm{p}<0.001)$. Similarly, the prevalence of periodontal disease was higher in subjects with abnormal triglyceride levels ( $\geq 150 \mathrm{mg} / \mathrm{dL})(38.3 \%)$ compared to those with normal levels $(24.3 \%)$ ( $\mathrm{p}<0.001)$. The prevalence of periodontal disease was $40.5 \%$ among subjects with systolic pressure $\geq 130 \mathrm{mmHg}$ or diastolic pressure $\geq 85 \mathrm{mmHg}$, which was higher than in those with normal blood pressure $(24.2 \%)(\mathrm{p}<0.001)$ (Table 3$)$.

\section{The effect of metabolic syndrome on periodontal disease}

Metabolic syndrome was defined as the presence of three or more components such as greater waist circumference, high fasting blood glucose, low HDL-cholesterol, high triglycerides, and hypertension. Based on our results, metabolic syndrome was found to have a significant effect on periodontal disease $(\mathrm{p}<0.001)$. The prevalence of periodontal disease in subjects with metabolic syndrome was approximately 1.443 times higher than that in the normal subjects (odds ratio, 1.443; $\mathrm{p}<0.001$ ) (Table 4).

\section{Discussion}

Metabolic syndrome refers to the simultaneous occurrence of hyperglycemia, hypertension, hypertriglyceridemia, hyperlipidemia (deficiency of HDL cholesterol), and abdominal obesity, which are major risk factors for cardiovascular disease. It is known that insulin resistance is the main cause of metabolic syndrome, and is emerging as one of the serious health problems worldwide ${ }^{11)}$.

The American Academy of Periodontology reports that the periodontal tissue functions as a reservoir of products, inflammation, and immune mediators caused by bacteria or bacterial groups, which are closely related to various systemic diseases, and that conversely, the periodontal disease is also affected by malnutrition or systemic disease, which may increase the risk of developing the disease. The academy emphasizes that dental specialists and medical professionals are responsible for educating the public regarding the importance of oral health to maintain general health.

This study used data from the sixth Korea National Health and Nutrition Examination Survey conducted from 2013 to 2015 to evaluate the relationship between metabolic syndrome and periodontal disease in Korean adults. The prevalence of periodontal disease was analyzed based on the socio-demographic characteristics, lifestyle habits, and presence of metabolic syndrome in the subjects.

A total of 12,686 subjects were included in this study, and the prevalence of periodontal disease was $33.7 \%$ in men and $23.1 \%$ in women, revealing a higher rate in men. This finding is in agreement with the results of the fourth Korea National Health and Nutrition Examination Survey ${ }^{12)}$. The prevalence of periodontal disease was significantly higher among older adults in our study, which is consistent with that reported by Page et al. ${ }^{13)}$. It is unclear whether progressive accumulation of periodontal lesions or the increased susceptibility of the host with advancing age leads to higher prevalence of periodontal disease ${ }^{14)}$. The proportion of periodontitis was higher in subjects who were involved in production and in those residing in eup-myeon areas. These results indicated that people living in the eup-myeon areas are less accessible when visiting dental clinics-hospitals than those living in Dong

Table 4. Association between the Presence of Metabolic Syndrome and Periodontitis

\begin{tabular}{lcccc}
\hline Variable (reference) & \multicolumn{4}{c}{ Periodontitis $^{*}$ p-value $^{\mathrm{a}}$} \\
\cline { 2 - 4 } & $\mathrm{B}$ & Exp (B) & $95 \%$ confidence interval & \\
Metabolic syndrome $^{\mathrm{b}}$ & & & $1.294 \sim 1.608$ & $<0.001$ \\
Yes & 0.366 & 1.443 & & \\
No & 0.000 & 1.000 & & \\
\hline
\end{tabular}

\footnotetext{
${ }^{\mathrm{a}} \mathrm{p}$-value by logistic regression.
}

${ }^{\mathrm{b}}$ Adjusted for age, gender, house income, education level, residential district, smoking status, intake of alcohol, and toothbrushing. 
area, and that job and income levels have affected. Lower prevalence of periodontal disease was observed in subjects with higher level of education and income. This observation is consistent with the results of several previous studies conducted in Korea ${ }^{15)}$. The level of education is a valuable indicator of health as it shows economically advantageous conditions due to the fact that higher education itself is a childhood environment. Education should address the disease by influencing the ability to select health behaviors and solve problems, and it is explained that it is advantageous to get social psychological economic resource and pride positively around. Therefore, planning and implementing national health policies are essential to reduce the prevalence of periodontal disease, taking into consideration the income, education, social capital, and region, among other factors.

In terms of oral health behaviors, the prevalence of periodontal disease was higher in subjects who brushed less frequently, and used lesser auxiliary oral hygiene products. These observations are consistent with those reported in the study by Won et al. ${ }^{16)}$. Therefore, the importance of maintenance of overall oral hygiene, including interdental cleaning, should be emphasized to prevent periodontal disease and metabolic syndrome. The prevalence of periodontal disease was higher in current smokers than past smokers, as well as in those who consumed alcohol frequently per week. Saito et al. ${ }^{17)}$ reported that smoking and drinking negatively affected periodontal disease, and that the periodontal index was significantly higher in smokers than non-smokers, which is consistent with the results of our study. The increased incidence of periodontal disease due to frequent alcohol consumption could be attributed to inhibition of the function of immune cells and subsequent bacterial infection. It has been hypothesized that maintenance of oral hygiene is neglected after excessive drinking.

The prevalence of periodontal disease was higher among subjects with abnormal components related to metabolic syndrome. Morita et al. $^{18)}$ analyzed the relationship between metabolic syndrome components and periodontal disease in Japanese workers. They reported that the incidence of periodontal disease was 1.6 times higher in subjects with body mass index (BMI) $\geq 25$ $\mathrm{kg} / \mathrm{m}^{2}, 1.2$ times higher in those with hypertension $(\geq 130 / 85$ $\mathrm{mmHg}), 1.9$ times higher in those with high fasting glucose $(\geq 110 \mathrm{mg} / \mathrm{dL})$, and 1.3 times higher in subjects with hypertriglyceridemia ( $\geq 150 \mathrm{mg} / \mathrm{dL}$ ). Moreover, subjects with metabolic syndrome were reported to have a 2.4-fold higher risk of periodontal disease. In addition, Kushiyama et al. ${ }^{19)}$ found that hypertension and low HDL cholesterol level were significantly associated with high CPI values, and Morita et al. ${ }^{18)}$ found that BMI, blood pressure, and triglyceride, fasting blood glucose, and HbA1c levels were significantly associated with periodontal pocket depths of $\geq 4 \mathrm{~mm}$.

Results of the multiple logistic regression analysis of subjects with metabolic syndrome and periodontal disease revealed that the prevalence of periodontal disease was 1.44 times higher in subjects with metabolic syndrome than in those without the syndrome. This result is consistent with several studies that reported higher incidence of periodontitis in patients with metabolic syndrome, when compared to those without the syndrome. Kushiyama et al. ${ }^{19)}$ reported a positive correlation between metabolic syndrome and periodontitis in 1,070 adults in Miyazaki city, Japan. In the case of the presence of metabolic syndrome as in this study, or there are a study reporting that each component of metabolic syndrome increases the risk of periodontitis and reports that there is the relevance of the inflammatory status of tissues due to periodontitis with metabolic syndrome ${ }^{20)}$, demonstrating that metabolic syndrome and periodontitis have a bidirectional influence. Therefore, dental healthcare workers should be able to distinguish patients with chronic diseases such as metabolic syndrome, diabetes, cardiovascular disease, and obesity that share common risk factors with periodontal disease. Furthermore, it is important to improve and maintain the health of teeth and periodontal tissues considering the interrelationship between oral infection and systemic diseases.

This study evaluated the association between metabolic syndrome and periodontitis; however, the causal relationship between the two conditions could not be determined due to the cross-sectional design. Despite these limitations, this study is meaningful, as it identified the association between metabolic syndrome and periodontitis in Korean adults 
using data from the National Health and Nutrition Examination Survey, with adequate significance. Further studies will be needed to clarify the causal relationship between metabolic syndrome and periodontitis.

\section{Notes}

\section{Conflict of interest}

No potential conflict of interest relevant to this article was reported.

\section{Ethical approval}

This study was exempted from review by the Institutional Review Board at Gangneung-Wonju University (IRB No. GWNUIRB-R2019-11).

\section{Author contributions}

Conceptualization: Jung-Hui Son, Soo-Myoung Bae. Data acquisition: Jung-Hui Son. Formal analysis: Jung-Hui Son, Soo-Myoung Bae. Writing original draft: Jung-Hui Son, Soo-Myoung Bae. Writing review and editing: Jung-Hui Son, Soo-Myoung Bae.

\section{ORCID}

Jung-Hui Son, https://orcid.org/0000-0003-3339-5902

Soo-Myoung Bae, https://orcid.org/0000-0002-1802-4129

\section{References}

1. Kim MK, Park JH: Metabolic syndrome. J Korean Med Assoc 55: 1005-1013, 2012. https://doi.org/10.5124/jkma.2012.55.10.1005

2. Girman CJ, Rhodes T, Mercuri M, et al.: The metabolic syndrome and risk of major coronary events in the Scandinavian Simvastatin Survival Study (4S) and the Air Force/Texas Coronary Atherosclerosis Prevention Study (AFCAPS/TexCAPS). Am J Cardiol 93: 136-141, 2004. https://doi.org/10.1016/j.amjcard.2003.09.028

3. Isomaa B, Almgren $\mathrm{P}$, Tuomi $\mathrm{T}$, et al.: Cardiovascular morbidity and mortality associated with the metabolic syndrome. Diabetes Care 24: 683-689, 2001. https://doi.org/10.2337/diacare.24.4.683

4. Lim J, Kim S, Ke S, Cho B: The prevalence of obesity, abdominal obesity and metabolic syndrome among elderly in general population. Korean J Fam Med 32: 128-134, 2011. https://doi.org/10.4082/kjfm.2011.32.2.128

5. Jin HJ, Choi YH, Lee SG, et al.: Relationship between metabolic syndrome and gingival health among Korean adolescents. J Korean Acad Oral Health 34: 628-635, 2010.

6. Ford ES, Giles WH, Dietz WH: Prevalence of the metabolic syndrome among US adults: findings from the third National Health and Nutrition Examination Survey. JAMA 287: 356-359, 2002. https://doi.org/10.1001/jama.287.3.356

7. Borgnakke WS: Hyperglycemia/diabetes mellitus and periodontal infection adversely affect each other. In: Genco RJ, Williams R, eds. Periodontal disease and overall health: a clinician's guide. 2nd ed. Professional Audience Communications, Yardley, pp.99-122, 2014.

8. D’Aiuto F, Nibali L, Parkar M, Patel K, Suvan J, Donos N: Oxidative stress, systemic inflammation, and severe periodontitis. J Dent Res 89: 1241-1246, 2010. https://doi.org/10.1177/0022034510375830

9. Korea Centers for Disease Control and Prevention: The sixth Korea National Health and Nutrition Examination Survey (KNHANES VI-3). Ministry of Health and Welfare, Cheongju, pp.3-5, 2015.

10. Saito T, Shimazaki Y, Sakamoto M: Obesity and periodontitis. N Engl J Med 339: 482-483, 1998. https://doi.org/10.1056/NEJM199808133390717

11. Dietz WH: Health consequences of obesity in youth: childhood predictors of adult disease. Pediatrics 101(3 Pt 2): 518-525, 1998.

12. Kwon YE, Ha JE, Paik DI, Jin BK, Bae KH: The relationship between periodontitis and metabolic syndrome among a Korean nationally representative sample of adults. J Clin Periodontol 38: 781-786, 2011. https://doi.org/10.1111/j.1600-051X.2011.01756.x

13. Page RC, Beck JD: Risk assessment for periodontal diseases. Int Dent J 47: 61-87, 1997. https://doi.org/10.1111/j.1875-595x.1997.tb00680.x

14. Kim MH, Yoon MS, Lim YH, et al.: The association between types of smoking and periodontal disease according to the survey year using the fourth and fifth Korea National Health and Nutrition Examination Surveys. J Dent Hyg Sci 17: 487-494, 2017. 
https://doi.org/10.17135/jdhs.2017.17.6.487

15. Jung JO: Effects of metabolic syndrome on periodontal diseases in Korean adults. J Dent Hyg Sci 12: 245-252, 2012.

16. Won YS, Choi $\mathrm{CH}, \mathrm{Oh} \mathrm{HN}$ : Risk factors of periodontal disease in Korean adults. J Korean Acad Oral Health 38: 176-183, 2014.

https://doi.org/10.11149/jkaoh.2014.38.3.176

17. Saito T, Shimazaki Y, Kiyohara Y, et al.: Relationship between obesity, glucose tolerance, and periodontal disease in Japanese women: the Hisayama study. J Periodontal Res 40: 346-353, 2005.

https://doi.org/10.1111/j.1600-0765.2005.00813.x
18. Morita T, Yamazaki Y, Mita A, et al.: A cohort study on the association between periodontal disease and the development of metabolic syndrome. J Periodontol 81: 512-519, 2010. https://doi.org/10.1902/jop.2010.090594

19. Kushiyama M, Shimazaki Y, Yamashita Y: Relationship between metabolic syndrome and periodontal disease in Japanese adults. J Periodontol 80: 1610-1615, 2009. https://doi.org/10.1902/jop.2009.090218

20. Kang HJ: A study on periodontal disease and tooth loss in metabolic syndrome patient. J Dent Hyg Sci 15: 445-456, 2015. https://doi.org/10.17135/jdhs.2015.15.4.445 